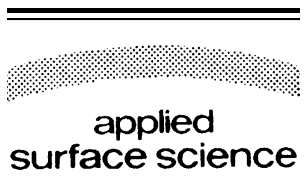

Applied Surface Science 247 (2005) 373-377

www.elsevier.com/locate/apsusc

\title{
Mechanical and electrochemical properties of multiple-layer diode laser cladding of 316L stainless steel
}

\author{
J. Dutta Majumdar ${ }^{\mathrm{a}, *}$, A. Pinkerton ${ }^{\mathrm{b}}$, Z. Liu ${ }^{\mathrm{c}}$, I. Manna ${ }^{\mathrm{a}}, \mathrm{L}_{\mathrm{Li}}{ }^{\mathrm{b}}$

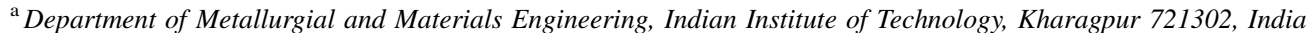 \\ ${ }^{\mathrm{b}}$ Department of Mechanical, Aerospace and Manufacturing Engineering, UMIST, P.O. Box 88, Manchester M60 1QD, UK \\ ${ }^{\mathrm{c}}$ Corrosion and Protection Centre, UMIST, P.O. Box 88, Manchester M601QD, UK
}

Available online 25 February 2005

\begin{abstract}
In the present investigation, a detailed mechanical and electrochemical properties of multiple-layer laser clad 316L stainless steel (from the powders produced by gas atomized route) has been carried out. Multiple-layer laser cladding of $316 \mathrm{~L}$ stainless steel has been conducted using a diode laser. The mechanical property (microhardness) of the fabricated product has been evaluated using a microhardness testing machine and correlated with the process parameters. The electrochemical property, mainly pitting corrosion resistance of the fabricated layer corresponding to maximum microhardness (in a $3.56 \% \mathrm{NaCl}$ solution) has been evaluated using standard potentiodynamic polarization testing. The microhardness of the laser assisted fabricated layers was found to vary from 170 to $278 \mathrm{VHN}$, increased with decrease in applied power density and increase in scan speed and was higher than that of conventionally processed $316 \mathrm{~L}(155 \mathrm{VHN})$. The superior microhardness value is attributed to grain refinement associated with laser melting and rapid solidification. The critical potential to pit formation $\left(E_{\mathrm{PP} 1}\right)$ was measured to be $550 \mathrm{mV}$ saturated calomel electrode (SCE) and superior to the conventionally processed 316L stainless steel (445 $\mathrm{mV}$ (SCE)).
\end{abstract}

(C) 2005 Elsevier B.V. All rights reserved.

Keywords: Microhardness; Pitting corrosion; Laser; 316L Stainless steel

\section{Introduction}

Laser, as a clean and directed source of energy has a wide scope of applications in materials processing $[1,2]$. Laser assisted surface melting and alloying of metals and alloys has been found to improve wear,

\footnotetext{
* Corresponding author. Tel.: +91 3222 283288; fax: +91 3222282280 .

E-mail address: jyotsna@metal.iitkgp.ernet.in (J. Dutta Majumdar).
}

corrosion and oxidation resistance [3-6]. High power laser beam may also be used to melt metals in the form of particles/wire, deposition of molten layer and thereby, building of a full component from the computer aided design (CAD) and it can be used to produce complex geometry [7]. Multiple-layer laser cladding has been reported to fabricate components made of TiAl intermetallics, Ni-based superalloys, steel and titanium [8-10]. 316L Stainless steel is an important class of stainless steel having a wide scope of application in oil and gas industry, refineries, 
chemical and petro-chemical plants and as biomaterials because of its excellent corrosion properties [11]. Pinkerton and $\mathrm{Li}$ [12] studied the influence of pulse frequency on the microstructure, surface roughness and hardness of fabricated 316L stainless steel using a pulsed wave $\mathrm{CO}_{2}$ laser. As an extension of previous attempt, a detailed study on laser assisted fabrication of AISI 316L has been carried out. It has been found that under a very narrow range of laser parameters a homogeneous microstructure with minimum area fraction of porosity can be achieved [13]. As a part of the study, in the present investigation, a detailed microhardness analysis of the fabricated layers have been made and correlated with microstructures. In addition, the pitting corrosion resistance of the formed layer has been evaluated and compared with the conventionally available 316L stainless steel.

\section{Experimental procedure}

In the present study, gas atomized $316 \mathrm{~L}$ stainless steel (C $<0.03 \%$, Si $0.7 \%$, Mn 1.7\%, Mo 3\%, Ni 11\%, Cr $18 \%$, balance $\mathrm{Fe}$ ) powders of particle size 50 $150 \mu \mathrm{m}$ was used as feedstock material. A Laserline diode laser of wavelength $940 \mathrm{~nm}$ (maximum power of $1.5 \mathrm{~kW}$ ) was used for the materials processing. Fabrication was done by melting the feedstock powder (delivered by an external powder feeder) using the laser, deposition of the melt on the substrate (mild steel) in a layer by layer fashion using an applied power density $(P)$ of $0.031-0.165 \mathrm{~kW} / \mathrm{mm}^{2}$, scan speed $(v)$ of $2.5-12.5 \mathrm{~mm} / \mathrm{s}$ and powder feed rate $\left(F_{\mathrm{P}}\right)$ of 65 to $340 \mathrm{mg} / \mathrm{s}$, respectively. After the laser processing, detailed microstructural study of the top surface and cross section of the fabricated component was carried out by optical and scanning electron microscopy. Microhardness of the fabricated layer (both on the top surface and along cross section) was carefully measured using a Tukon 2100 Vicker's microhardness tester with a $300 \mathrm{~g}$ applied load and correlated with process parameters. Finally, corrosion test was carried out for the sample corresponding to maximum microhardness using a ACM Gill AC potentiostat with SEQUENCER software. Pitting corrosion behaviour was evaluated by standard cyclic potentiodynamic polarization study [14]. The specimen was carefully polished using $6 \mu \mathrm{m}$ diamond paste prior to corrosion study. Standard cyclic potentiodynamic polarization test was performed at a sweep rate of $0.5 \mathrm{mV} / \mathrm{s}$ in aerated $3.56 \% \mathrm{NaCl}$ solution. The experiment was conducted at $20{ }^{\circ} \mathrm{C}$. A saturated calomel electrode (SCE) was employed as the reference electrode. A platinum electrode was used as counter electrode for current measurement. The solution was prepared from analytically pure chemicals and deionised water. The specimen was exposed to the test conditions for $2 \mathrm{~h}$ open circuit potential (OCP) before commencing the test.

\section{Results and discussions}

Microstructural homogeneity and defect free matrix are the pre-requisite for the superior mechanical and electrochemical properties of any component. A detailed study on the variation of microstructure and its homogeneity with the laser parameters showed that under a very narrow range of processing conditions a uniform and homogeneous microstructure may be achieved [13]. Fig. 1 shows the microstructure of laser assisted fabricated $316 \mathrm{~L}$ stainless steel lased with a power density of $0.073 \mathrm{~kW} / \mathrm{mm}^{2}$, scan speed of $5 \mathrm{~mm} /$ $\mathrm{s}$ and a powder feed rate of $203 \mathrm{mg} / \mathrm{s}$ (one of the optimum processing conditions). The microstructure is predominantly cellular, with an average grain size of $10 \mu \mathrm{m}$. However, the morphology and grain size of the microstructure were found to vary with laser parameters [13]. The microhardness analysis of the

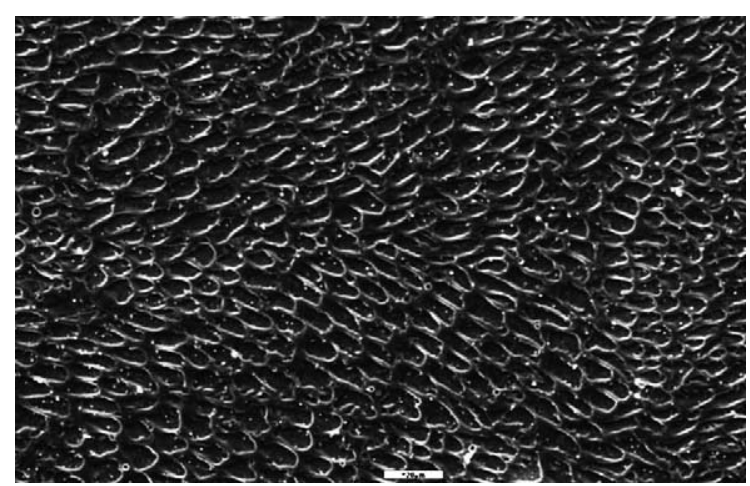

Fig. 1. Scanning electron micrograph of laser assisted fabricated $316 \mathrm{~L}$ stainless steel lased with a power of $0.073 \mathrm{~kW} / \mathrm{mm}^{2}$, scan speed of $5 \mathrm{~mm} / \mathrm{s}$ and a powder feed rate of $203 \mathrm{mg} / \mathrm{s}$. 


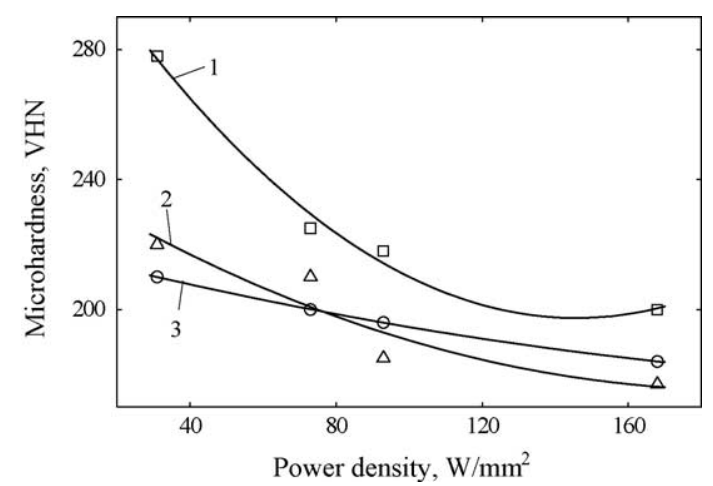

Fig. 2. Variation of average microhardness with applied power density for laser assisted fabricated AISI 316L stainless steel lased with a (1) scan speed of $5 \mathrm{~mm} / \mathrm{s}$, powder feed rate of $203 \mathrm{mg} / \mathrm{s}$; (2) scan speed of $2.5 \mathrm{~mm} / \mathrm{s}$, powder feed rate of $203 \mathrm{mg} / \mathrm{s}$ and (3) scan speed of $2.5 \mathrm{~mm} / \mathrm{s}$, powder feed rate of $136 \mathrm{mg} / \mathrm{s}$, respectively.

fabricated product showed that the average microhardness varied from 170 to $280 \mathrm{VHN}$ which is significantly higher than the microhardness values of conventionally processed annealed $316 \mathrm{~L}$ stainless steel $(155 \mathrm{VHN})$ and even that of the same fabricated by pulsed wave $\mathrm{CO}_{2}$ laser $[11,12]$. The microhardness value was however, found to vary with laser parameters. Fig. 2 shows the effect of applied laser power density on the average microhardness of laser assisted fabricated AISI 316L stainless steel lased with a (1) scan speed of $5 \mathrm{~mm} / \mathrm{s}$, powder feed rate of $203 \mathrm{mg} / \mathrm{s}$; (2) scan speed of $2.5 \mathrm{~mm} / \mathrm{s}$, powder feed rate of $203 \mathrm{mg} / \mathrm{s}$; (3) scan speed of $2.5 \mathrm{~mm} / \mathrm{s}$, powder feed rate of $136 \mathrm{mg} / \mathrm{s}$, respectively. From Fig. 2, it is relevant that average microhardness of the fabricated layers decreases with increase in applied power density. This effect is attributed to coarsening of grains as was evident in detailed microstructural investigation [13]. A close comparison of plot 1 with plot 2 shows that average microhardness value increases with increase in scan speed. With increasing the scan speed, due to a shorter time of interaction a low energy is supplied during melting resulting in refinement of grains, and hence, increase in average microhardness. The effect of powder flow rate on the microhardness does not however, show any specific trend (plot 2 vis-à-vis plot 3). From the variation of microhardness with laser parameters it may be concluded that hardening of the formed parts is mainly because of grain refinement and for an

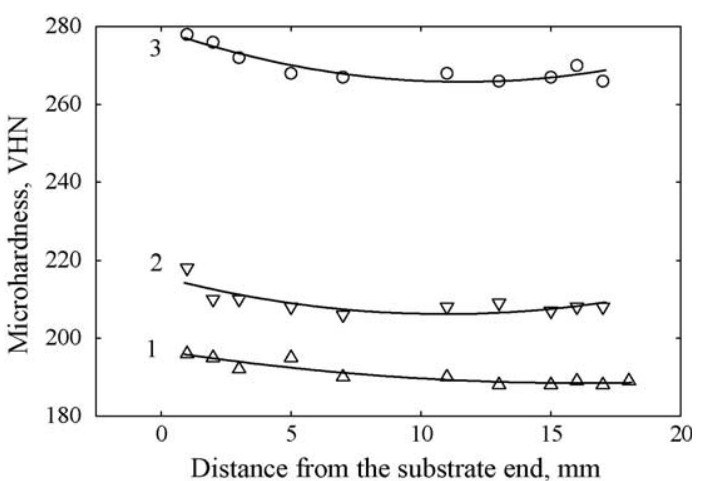

Fig. 3. Variation of microhardness with length for laser assisted fabricated AISI 316L stainless steel processed with (1) a power density of $0.091 \mathrm{~kW} / \mathrm{mm}^{2}$, scan speed of $2.5 \mathrm{~mm} / \mathrm{s}$; (2) a power density of $0.091 \mathrm{~kW} / \mathrm{mm}^{2}$, scan speed of $5 \mathrm{~mm} / \mathrm{s}$ and (3) a power density of $0.031 \mathrm{~kW} / \mathrm{mm}^{2}$, scan speed of $5 \mathrm{~mm} / \mathrm{s}$ (with a powder feed rate of $136 \mathrm{mg} / \mathrm{s}$ ), respectively.

improved microhardness, a low power and high scan speed combinations should be chosen.

Fig. 3 shows the variation of average microhardness along the wall growth direction for laser assisted fabricated AISI 316L stainless steel processed with (1) a power density of $0.091 \mathrm{~kW} / \mathrm{mm}^{2}$, scan speed of $2.5 \mathrm{~mm} / \mathrm{s}$; (2) $0.091 \mathrm{~kW} / \mathrm{mm}^{2}, 5 \mathrm{~mm} / \mathrm{s}$; (3) $0.031 \mathrm{~kW} /$ $\mathrm{mm}^{2}, 5 \mathrm{~mm} / \mathrm{s}$ (with a powder feed rate of $136 \mathrm{mg} / \mathrm{s}$ ), respectively. It is relevant from Fig. 3 that the microhardness is almost uniform throughout the cross section along the wall height with a marginal higher value near to the substrate and a lower value at the intermediate region. The marginal higher value of microhardness near the substrate region is mainly because of refinement of microstructure due to a high quenching rate from the underlying substrate. On the other hand, lower level of microhardness at the intermediate region is attributed to the grain coarsening effect. Application of a lower power density (plot 3 vis-à-vis plot 2) increases the average microhardness. Similarly, application of a lower scan speed (plot 1 visà-vis plot 2), increases the average microhardness of the fabricated layer. Hence, the microhardness of the fabricated layer marginally varies with the position and highly dependent on the applied laser parameters.

Fig. 4 presents the results of the potentiodynamic polarization test conducted in a $3.56 \mathrm{wt} . \% \mathrm{NaCl}$ solution for the sample lased with a power density of $0.031 \mathrm{~kW} / \mathrm{mm}^{2}$, scan speed of $5 \mathrm{~mm} / \mathrm{s}$ and powder feed rate of $136 \mathrm{mg} / \mathrm{s}$ (the condition corresponding to 


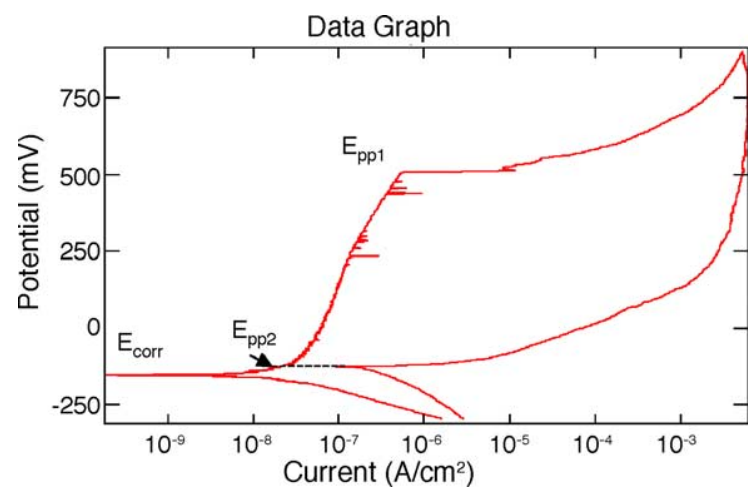

Fig. 4. Potentiodynamic cyclic polarization behaviour of direct laser fabricated $316 \mathrm{~L}$ stainless steel (lased with a power of $0.031 \mathrm{~kW} / \mathrm{mm}^{2}$, scan speed of $5 \mathrm{~mm} / \mathrm{s}$ and powder feed rate of $136 \mathrm{mg} / \mathrm{s}$ ) in a $3.56 \% \mathrm{NaCl}$ solution.

maximum microhardness value). The polarization test was conducted both in forward and reverse potential cycles to determine the critical potential for pit formation $\left(E_{\mathrm{pp} 1}\right)$ and pit growth $\left(E_{\mathrm{pp} 2}\right)$ values. Critical potential for pit formation is represented by $\left(E_{\mathrm{pp} 1}\right)$ which is the potential at which the current density increases very rapidly with a slight change in potential and higher the $E_{\mathrm{pp} 1}$ greater is the resistance of the material to pit formation [15]. On the other hand, $E_{\mathrm{pp} 2}$ is the potential where the reverse cycle intersects the forward cycle. Nobler the $E_{\mathrm{pp} 2}$ to $E_{\mathrm{corr}}$, superior is the resistance of the material to pit growth. Table 1 summarizes the pitting potentials of the present samples under the given study. For comparison, the $E_{\mathrm{pp} 1}$ value of AISI 316L stainless steel under annealed condition is also shown in Table 1 [16]. From Table 1 is may be noted that $E_{\mathrm{pp} 1}$ value achieved for the present sample is $550 \mathrm{mV}(\mathrm{SCE})$, which is higher than that for the conventionally processed AISI $316 \mathrm{~L}$ stainless steel, i.e. $425 \mathrm{mV}(\mathrm{SCE})$. Moreover, $E_{\mathrm{pp} 2}$ is more nobler than the corresponding oxygen evolution

Table 1

Comparison of corrosion properties of laser assisted fabricated visà-vis conventional 3161 stainless steel

\begin{tabular}{lcll}
\hline Sample & $\begin{array}{l}E_{\mathrm{corr}} \\
(\mathrm{mV} / \mathrm{SCE})\end{array}$ & $\begin{array}{l}E_{\mathrm{pp} 1} \\
(\mathrm{mV} / \mathrm{SCE})\end{array}$ & $\begin{array}{l}E_{\mathrm{pp} 2} \\
(\mathrm{mV} / \mathrm{SCE})\end{array}$ \\
\hline Conventional & 0 & 425 & $\mathrm{NA}$ \\
$\begin{array}{c}\text { Laser assisted } \\
\text { fabricated (present study) }\end{array}$ & -150 & 550 & -125 \\
\hline
\end{tabular}

potential $\left(E_{\text {corr }}\right)$, hence, pit propagation is also precluded for the laser assisted fabricated 316L stainless steel at the oxygen evolution potential.

\section{Summary and conclusions}

In the present study, the mechanical (microhardness) and electrochemical (pitting corrosion resistance) analysis of laser assisted fabricated AISI316L stainless steel has been carried out (with a power density of $0.031-0.168 \mathrm{~kW} / \mathrm{mm}^{2}$, scan speed of 5$7.5 \mathrm{~mm} / \mathrm{s}$ and powder feed rate of $136-203 \mathrm{mg} / \mathrm{s}$ ).

From the results, the following conclusions may be drawn:

1. The average microhardness of the fabricated layer was significantly improved to as high as 170-280 VHN as compared to $155 \mathrm{VHN}$ of conventionally processed and $175 \mathrm{VHN}$ of $\mathrm{CO}_{2}$ laser assisted fabricated 316L stainless steel. The enhanced microhardness is attributed to grain refinement achieved during laser processing.

2. Microhardness was found to be marginally higher at the near substrate region and reduced at the intermediate region. Average microhardness of the fabricated layer decreased with increase in applied laser power density and decrease in scan speed.

3. Pitting corrosion resistance was marginally improved in terms of critical potential of pit formation (which is $550 \mathrm{mV}$ (SCE) in the present study as compared to $440 \mathrm{mV}$ (SCE) of the conventionally processed one).

\section{Acknowledgement}

The financial support from Department of Science and Technology, India (BOYSCAST SCHEME) to JDM for the present study is gratefully acknowledged.

\section{References}

[1] W.M. Steen (Ed.), Laser Material Processing, Springer Verlag, New York, 1991.

[2] J. Dutta Majumdar, I. Manna, Sadhana (2003) 495-562.

[3] C.W. Draper, J.M. Poate, Inter. Met. Rev. 30 (1985) 85-108. 
[4] J. Dutta Majumdar, I. Manna, Mater. Sci. Eng. A 268 (1999) 216-226.

[5] B.L. Mordike, in: R.W. Cahn, P. Haasen, E.J. Kramer (Eds.), Materials Science and Technology, vol. 15, VCH, Weinheim, 1993, p. 111.

[6] P.A. Molian, in: T.S. Sudarshan (Ed.), Surface Modification Technologies - An Engineers Guide, Marcel Dekker Inc., New York, 1989, p. 421.

[7] J. Laeng, J.G. Stewart, F.W. Liou, Int. J. Production Res. 38 (2000) 3973-3996.

[8] D. Srivastava, I.T.H. Chang, M.H. Loretto, Intermetallics 9 (2001) 1003-1013.

[9] C.L. Atwood, M.L. Griffith, L.D. Harwell et al., Laser spray fabrication for net-shape rapid product realization LDRD, Sandia Report, 1999.
[10] F.G. Arcella, F.H. Froes, J. Met. 52 (5) (2000) 28-30.

[11] C.J. Novak, in: D. Peckner, I.M. Bernstein (Eds.), Handbook of Stainless Steels, McGraw-Hill, New York, 1977, pp. 1-4.

[12] A.J. Pinkerton, L. Li, Appl. Surf. Sci. 208-209 (2003) 405410.

[13] J. Dutta Majumdar, Z. Liu, I. Manna, A. Pinkerton, L. Li, in: Proceedings of the EMRS Spring Meeting, 2004.

[14] Standard Recommended Practice for Conducting Cyclic Potentiodynamic Polarization Measurements for Localized Corrosion, Annual Book of ASTM Standards, Am. Soc. For Testing of Metals, Philadelphia, 1985. p. G61.

[15] M.G. Fontana (Ed.), Corrosion Engineering, McGraw-Hill, New York, 1987, p. 71.

[16] T.M. Yue, J.K. Yu, H.C. Man, Surf. Coat. Technol. 137 (2001) 65. 